\title{
Alkaline Hydrothermal Treatment of the Waste Produced in the Semi-Dry Flue Gas Desulfurization System
}

\author{
Lucas Caetano Grosche, Tharcila Colachite Rodrigues Bertolini, Denise Alves Fungaro \\ Instituto de Pesquisas Energéticas e Nucleares, IPEN-CNEN/SP, 2242 Prof. Lineu Prestes Av. , Cidade \\ Universitária, São Paulo, SP, Brazil
}

*Corresponding Author: Lucas Caetano Grosche, Instituto de Pesquisas Energéticas e Nucleares, IPEN-CNEN/SP, 2242 Prof. Lineu Prestes Av. , Cidade Universitária, São Paulo, SP, Brazil

\begin{abstract}
Semi-dry flue gas desulfurization (FGD) material is a byproduct generated from the desulfurization system of coal-fired power station. The beneficial reuse application for dry FGD material is relatively undeveloped. FGD was used as raw material for the synthesis of value-added materials by alkaline hydrothermal treatment. Different experimental conditions, such as, reaction time, temperature, alkali hydroxide concentration and solid/liquid ratio were studied. Raw material and synthesis products were characterized by XRD, XRF, particle size analyser, TG-DTG-DTA, and FGD was classified according to Brazilian Environmental Regulations. The results show that dry FGD has a higher $\mathrm{CaO}$ and $\mathrm{SO}_{3}$ content and the major minerals present in material are hannebachite, anhydrite, calcite, portlandite, gehlenite and sodium carbonate. The size of dry FGD ash particles is around 0.399-355.656 $\mu \mathrm{m}$ with median diameter of $7.63 \mu \mathrm{m}$. Thermal behaviour of FGD was characterised by the existence of six and four stages under air and inert atmosphere, respectively. FGD can be classified as Class II A material (non-dangerous/non-inert). The presence of zeolite hydroxysodalite confirms successful conversion of FGD into zeolitic material after activation in $\mathrm{NaOH}$ solutions. Along with the zeolitic product were obtained katoite, hydrocalumite and Alsubstituted tobermorite. All synthesised materials present ionic exchange capacity and could be used as a low-cost adsorbent. FGD utilisation minimises the environmental impact of disposal problems and further enables an application for treatment of wastewater.
\end{abstract}

Keywords: Flue gas desulfurization products; coal ash; alkaline hydrothermal treatment

\section{INTRODUCTION}

Combustion of sulfur-containing fuels, such as coal, results in sulfur dioxide $\left(\mathrm{SO}_{2}\right)$ formation. Sulfur oxide emissions are known to cause detrimental impacts on human health and the environment, such as the formation of acid rain [1].

Coal fired power plants installed flue gas desulfurization (FGD) technology for reducing $\mathrm{SO}_{2}$ emissions as result of environmental legislation [2]. The two most common scrubber technology used is wet or dry/semi-dry systems.

In wet FGD system, the flue gas is ducted to a spray chamber/vessel (absorber) where an aqueous solution, of sorbent (limestone or lime), is injected into the flue gas[2].

In semi-dry FGD systems, the sorbent (lime or calcium hydroxide) mixed with water is sprayed into the hot flue gas in the spray dryer absorber (SDA) in a cloud of fine droplets. The residence time is sufficient to allow the $\mathrm{SO}_{2}$ and other acid gases to react simultaneously with the sorbent and for the water to evaporate. The product produced from an SDA system is a dry FGD material commonly referred to as SDA material or dry FGD material[3]-[5].

The significant difference in the FGD material produced from these two systems is the relative proportion of calcium sulfite and calcium sulfate. The primary product of dry FGD systems is calcium sulfite with minor amounts of calcium sulfate, unreacted calcium-based absorbent and some amount of fly ash.

In both cases, the removal of $\mathrm{SO}_{2}$ from flue gases results in a solid residue that must either be disposed or utilised in a beneficial manner. For the wet FGD process, there already exists a market 
demand for gypsum. However, the utilisation of the dry FGD byproduct is very difficult due to its constituent complexity.

Calcium sulfite to sulfate proportion affects physical properties of dry FGD materials, and with the many available FGD technologies, there is significant variability in their characteristics. FGD material with high concentrations of sulfite poses dewatering problem. Besides that, sulfite sludges settle and filter poorly and are thixotropic[2], [3].

A small fraction of dry FGD has been utilised mainly in roadbed materials, mining applications and concrete products[2], [6]. Therefore, it is essential to develop alternative techniques to utilise dry/semi-dry FGD residue

In this study, different reaction parameters of hydrothermal treatment were tested to obtain valueadded materials (e.g., Hydrotalcite-like compounds, zeolite) from dry FGD residue. The chemical compositions, mineralogy and others properties of dry FGD material and the resulting synthesised products were analysed.

\section{MATERIAL AND METHODS}

\subsection{Materials}

All the reagents used for experimental studies were of analytical grade. Semi-dry FGD sample, (FGD), was collected from a location in USA representing the dominant type of dry FGD scrubbing technologies developed by Babcock \& Wilcox Power Generation Group, Inc.'s and used in Xcel Energy's coal-fired stations. The sample was stored in the laboratory at room temperature (approximately $25^{\circ} \mathrm{C}$ ) without any change in your properties.

\subsection{Conventional Hydrothermal Synthesis}

FGD was mixed with aqueous $\mathrm{NaOH}$ solution in a Teflon vessel in a pre-determined ratio. This mixture was heated in the oven, and after hydrothermal treatment, the reaction mixtures were filtered and washed with distilled water until the washing water had $\mathrm{pH} \sim 11$ and the synthesis products were oven dried at $50{ }^{\circ} \mathrm{C}$ for $12 \mathrm{~h}$. The reaction temperature $\left(80-100^{\circ} \mathrm{C}\right)$, reaction time $(24-48 \mathrm{~h}), \mathrm{NaOH}$ concentration (1.0-5.0 mol L $\mathrm{L}^{-1}$ ) and mass of $\mathrm{FGD} / \mathrm{NaOH}$ solution volume ratio $\left(0.06-0.25 \mathrm{~g} \mathrm{~mL}^{-1}\right)$ were varied as control parameters.

\subsection{Characterization of Material}

The mineralogical compositions were determined by X-ray diffraction analyses (XRD) with an automated Rigaku miniflex 2 diffractometer with $\mathrm{Cu}$ anode using $\mathrm{Co} \mathrm{K} \alpha$ radiation at $40 \mathrm{kV}$ and 20 $\mathrm{mA}$ over the range $(2 \theta)$ of $5-80^{\circ}$ with a scan time of $0.5^{\circ} / \mathrm{min}$. The chemical composition was determined by X-ray fluorescence (XRF) in Rigaku RIX- 3000 equipment. The particle size of the materials was measured using a laser based particle size analyser, namely a Malvern MSS Mastersizer 2000 Ver. 5.54.Thermal analysis was carried on Universal V4.1 DTA Instruments in the temperature range of $0-1200{ }^{\circ} \mathrm{C}$ under air and inert atmosphere with a flow of $100.0 \mathrm{~mL}$ min- 1 and heating rate of $10{ }^{\circ} \mathrm{C} \mathrm{min}^{-1}$. Leaching and solubilisation were tested according to Norm ABNT NBR 10005 [7] and 10006 [8], respectively. Others physical-chemical have been described in a previous paper[4].

\section{RESULTS AND DISCUSSION}

\subsection{Characterizations of FGD}

\subsubsection{Physicochemical Properties}

The chemical composition of FGD, as well as its loss on ignition (LOI), is provided by Table 1 . The major elements are $\mathrm{CaO}$ and $\mathrm{SO}_{3}$. The main impurities are some $\mathrm{SiO}_{2}$ and $\mathrm{Al}_{2} \mathrm{O}_{3}$, which could come from an amorphous phase of fly ash and crystal phase of quartz and the impurity of limestone. Further, $\mathrm{Fe}_{2} \mathrm{O}_{3}, \mathrm{MgO}$ and $\mathrm{Na}_{2} \mathrm{O}$ are the common oxides found in fly ash. The chloride content may be due to the lime scrubber in the air pollution control system, which removes acidic gases such as $\mathrm{HCl}$.

Unlike fly ash or bottom ash, neither the parent coal nor the boiler conditions have a significant effect on the physical or chemical properties of the FGD byproducts. In the place of the characteristics of the FGD byproducts are intensely composed by the type of reagent used, the operating temperature, 
Alkaline Hydrothermal Treatment of the Waste Produced in the Semi-Dry Flue Gas Desulfurization System

pressure, and degree of oxidation within the scrubbing unit and the amount of water used to distribute the reagent through the flue gas[9].

Table1. Chemical composition of FGD

\begin{tabular}{|l|l|l|l|}
\hline Elements & $(\%$ wt $)$ & Elements & $(\%$ wt $)$ \\
\hline $\mathrm{CaO}$ & 25.2 & $\mathrm{SrO}$ & 0.12 \\
\hline $\mathrm{SO}_{3}$ & 24.5 & $\mathrm{Cl}$ & 0.11 \\
\hline $\mathrm{SiO}_{2}$ & 7.76 & $\mathrm{MnO}$ & 0.04 \\
\hline $\mathrm{Al}_{2} \mathrm{O}_{3}$ & 4.53 & $\mathrm{CuO}$ & 0.02 \\
\hline $\mathrm{Fe}_{2} \mathrm{O}_{3}$ & 3.26 & $\mathrm{Cr}_{2} \mathrm{O}_{3}$ & 0.01 \\
\hline $\mathrm{MgO}$ & 1.56 & $\mathrm{Co}_{3} \mathrm{O}_{4}$ & 0.01 \\
\hline $\mathrm{Na}_{2} \mathrm{O}$ & 0.76 & $\mathrm{ZnO}$ & 0.01 \\
\hline $\mathrm{P}_{2} \mathrm{O}_{5}$ & 0.62 & $\mathrm{ZrO}_{2}$ & 0.01 \\
\hline $\mathrm{TiO}_{2}$ & 0.52 & $\mathrm{Nb}_{2} \mathrm{O}_{5}$ & 0.01 \\
\hline $\mathrm{K}_{2} \mathrm{O}$ & 0.28 & Others & $<001$ \\
\hline $\mathrm{BaO}$ & 0.15 & LOI & 30.5 \\
\hline
\end{tabular}

TABLE 2 summarises others important properties for FGD waste. The specific mass value corresponds to a material containing particles with glass phase of quartz and mullite, and similar values were found for fly ash samples[10].

Table2. Characteristics of FGD waste

\begin{tabular}{|l|l|}
\hline Characteristic & Value \\
\hline Free water & $0.74 \%$ \\
\hline Combined water & $3.37 \%$ \\
\hline Insoluble residue & $16.7 \%$ \\
\hline $\mathrm{SO}_{3}$ - in terms of $\mathrm{SO}_{2}$ & $12.2 \%$ \\
\hline Total sulphuric anhydride & $18.3 \%$ \\
\hline $\mathrm{SO}_{4}$ - in terms of $\mathrm{SO}_{3}$ & $6.1 \%$ \\
\hline Carbonic anhydride & $16.3 \%$ \\
\hline Specific mass & $2.13 \mathrm{~g} \mathrm{~cm}^{-3}$ \\
\hline Bulk density ("unit weight") & $0.59 \mathrm{~g} \mathrm{~cm}^{-3}$ \\
\hline
\end{tabular}

\subsubsection{Mineralogical Compositions}

XRD patterns of FGD as shown in Fig. 1. The XRD results showed that in the FGD products the main mineralogical phases are $\mathrm{CaSO}_{3} .0 .5 \mathrm{H}_{2} \mathrm{O}$ (hannebachite), $\mathrm{Ca}(\mathrm{OH})_{2}$ (portlandite), $\mathrm{CaCO}_{3}$ (calcite), $\mathrm{CaSO}_{4}$ (anhydrite), $\mathrm{Ca}_{2} \mathrm{Al}_{2} \mathrm{SiO}_{7}$ (gehlenite) and $\mathrm{Na}_{2} \mathrm{CO}_{3}$ (sodium carbonate).

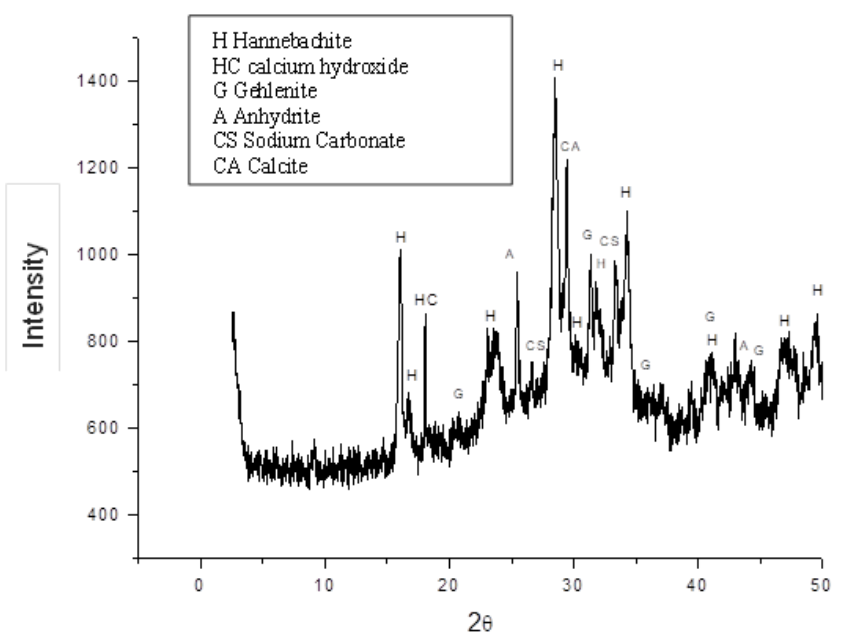

Figure1. XRD patterns of FGD

During the FGD processes, lime or slaked lime particles absorb the sprayed water in the reactor, and a water film forms around the particle. Then, $\mathrm{SO}_{2}$ gas dissolves in the water and reacts with $\mathrm{Ca}(\mathrm{OH})_{2}$ to 
generate $\mathrm{CaSO}_{3} \cdot 0.5 \mathrm{H}_{2} \mathrm{O}$. Portlandite was derived from the use of an excess adsorbent. The adsorbent calcines at that temperature to form $\mathrm{CaO}$, which then reacts with $\mathrm{SO}_{2}$ and $\mathrm{O}_{2}$ in the flue gas to form $\mathrm{CaSO}_{4}$ products[4], [5].

The presence of $\mathrm{CaCO}_{3}$ in the same sample indicates re-carbonation of $\mathrm{Ca}(\mathrm{OH})_{2}$ by reaction with atmospheric $\mathrm{CO}_{2}$. Sodium carbonate was identified as a highly efficient to remove $\mathrm{SO}_{\mathrm{x}}$ and is also used as an adsorbent in FGD technology[11].

Although the main cation involved in the FGD product formation is calcium, silicon also has an important role. In addition to calcium phases, only silicon minerals have been observed in significant amounts. The reaction between quartz present in unreacted fly ash and calcium carbonate produces gehlenite. The occurrence of this siliceous phase in the FGD sample is evidence of the involvement of silicon in several reactions[12], [13].

\subsubsection{Particle Size Distribution}

Particle-size distribution is essential because many engineering parameters are related to the variation of particle size of a material. Besides, the finer the particle size of the FGD the higher its specific surface area will be, which is important in evaluating its utilisation options. Particle sizes depend on both combustion and collection system designs.

Fig. 2 reports the differential and cumulative particle size distributions for FGD. The differential size distribution of the material is relatively uniform with the expected normal bell-shaped distribution curve. The material tends to show a trimodal particle size distribution.

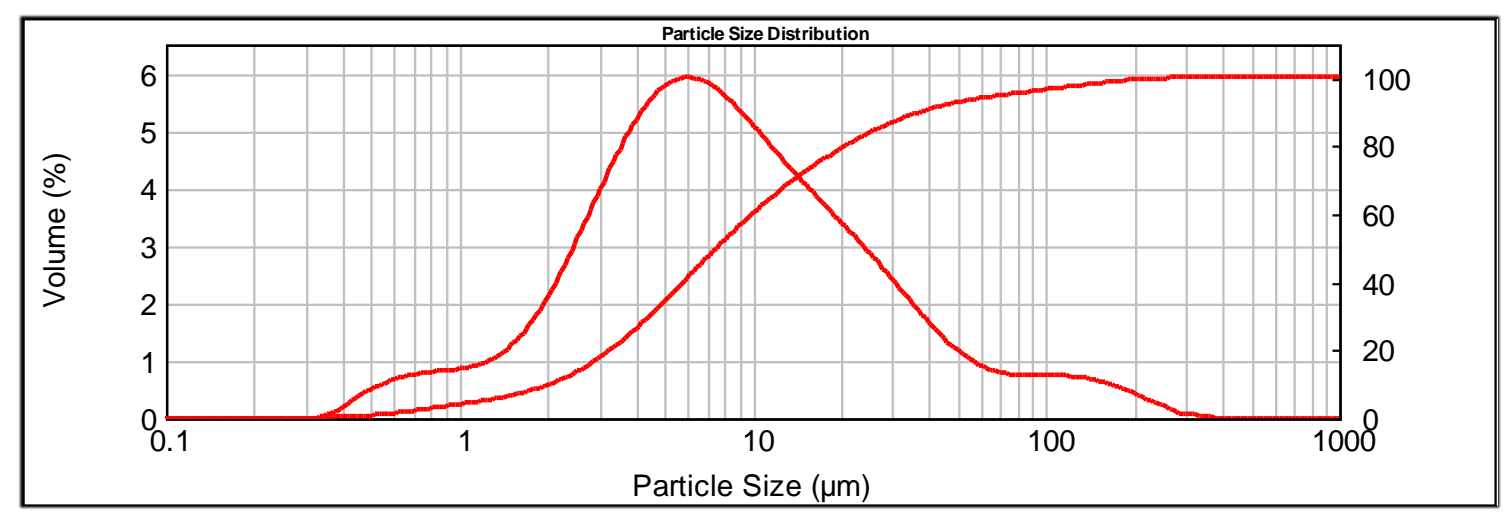

Figure2. Particle size distribution of FGD

The particle size distributions of material are given in Table 3. These distributions specify that the majority of particles $(90 \%)$ lie below $37.976 \mu \mathrm{m}$. Therefore the material can be classified in the silt size range $(1 / 256-1 / 16 \mathrm{~mm}$, or $3.9-62.5 \mu \mathrm{m})$. The particle size distribution ranged from $0.399 \mu \mathrm{m}$ to $355.656 \mu \mathrm{m}$. It was reported in the literature that $78 \%-80 \%$ of the dry FGD material was in the fraction finer than $40 \mu \mathrm{m}[2]$.

Table3. Particle size distributions of material

\begin{tabular}{|l|l|}
\hline & Particle diameter \\
\hline D10 $(\mu \mathrm{m})$ & 2.008 \\
\hline D50 $(\mu \mathrm{m})$ & 7.630 \\
\hline $\mathrm{D} 90(\mu \mathrm{m})$ & 37.976 \\
\hline $\mathrm{D}([3,2])$ & 4.391 \\
\hline
\end{tabular}

\subsubsection{Thermal Properties}

The results of the TG/DTG and DTA analysis of FGD are presented in FIGURE 3 under air atmosphere and FIGURE 4 in an argon atmosphere. TABLE 4 and 5 shows the values of mass loss as a function of temperature under air and argon atmosphere, respectively. 


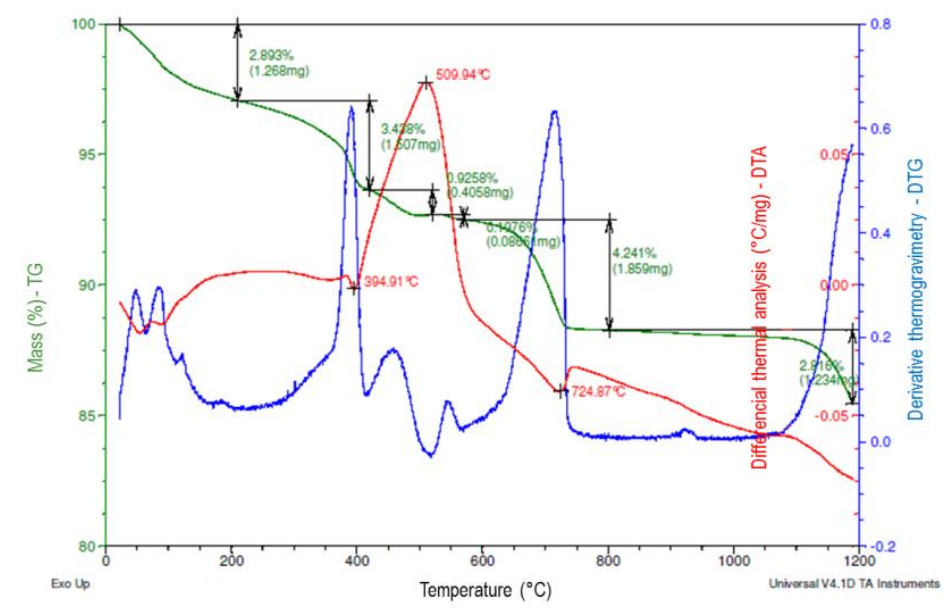

Figure3. TG/DTG and DTA curves of FGD under air

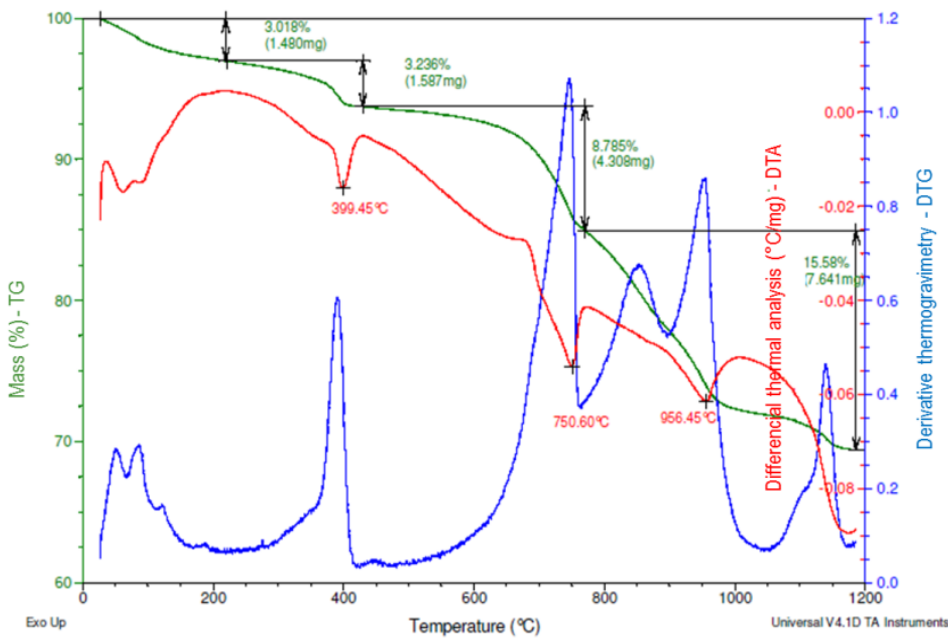

Figure4. TG/DTG and DTA curves of FGD under argon

Table4. $T G$ results in air atmosphere (in $100 \mathrm{~mL} \mathrm{~min}^{-1}$ air gas flow)

\begin{tabular}{|l|l|}
\hline Temperature Interval $\left({ }^{\circ} \mathrm{C}\right)$ & Weight loss $(\%)$ \\
\hline $25-210$ & 2.89 \\
\hline $210-420$ & 3.44 \\
\hline $420-520$ & 0.93 \\
\hline $520-570$ & 0.20 \\
\hline $570-800$ & 4.24 \\
\hline Above 800 & 2.82 \\
\hline
\end{tabular}

Table5. TG results in inert atmosphere (in $100 \mathrm{~mL} \mathrm{~min}^{-1}$ argon gas flow)

\begin{tabular}{|l|l|}
\hline Temperature Interval $\left({ }^{\circ} \mathrm{C}\right)$ & Weight loss $(\%)$ \\
\hline $25-220$ & 3.02 \\
\hline $220-430$ & 3.24 \\
\hline $430-770$ & 8.79 \\
\hline Above 770 & 15.6 \\
\hline
\end{tabular}

Thermal behaviour of FGD is characterised by the existence of six stages under an air atmosphere (TABLE 4). The first mass lost step corresponds to the loss of moisture and the loss of water chemically bounded by hydrated $\mathrm{CaCl}_{2}$. The second stage is due $\mathrm{CaSO}_{3} \cdot 0.5 \mathrm{H}_{2} \mathrm{O}$ dehydration and decomposition of an admixture of magnesium compounds are too possible within this range of temperature. The presence of unreacted sorbent $\mathrm{Ca}(\mathrm{OH})_{2}$ in FDG is confirmed by the 3rd thermal decomposition between $420-520{ }^{\circ} \mathrm{C}$, due to their dehydroxylation. The fourth stage is due to the 

System

oxidation of $\mathrm{CaSO}_{3}$ by oxygen to $\mathrm{CaSO}_{4}$. Calcite thermal decomposition occurs in fifth decomposition step. Loss of mass above $800{ }^{\circ} \mathrm{C}$ results from the release of anhydrous sulfur dioxide (6th stage).

Under inert atmosphere, TG patterns can be categorized in four visible stages of weight loss (TABLE 5). The different decomposition stages are similar to an oxidative atmosphere. The exception is the stage corresponded to oxidation of $\mathrm{CaSO}_{3}$ that was not observed. Besides, the weight loss produced between 430 and $770{ }^{\circ} \mathrm{C}$ due to $\mathrm{Ca}(\mathrm{OH})_{2}$ dehydroxylation and calcite decomposition occurred in only one stage (3rd stage).

The obtained thermal analyses were very similar with literature data for other semi-dry FGD samples collected in different installations showing that the desulfurization process did not influence the thermal behaviour of these wastes[3], [4].

\subsubsection{Leaching and Solubilisation Tests}

FGD sample was submitted to leaching and solubilisation tests for solid waste classification according to Brazilian regulation.

Leaching test was carried out to assess whether the waste is hazardous or not. The procedure is established by Norm NBR 10005 [7], which is similar to the toxicity characteristic leaching procedure (TCLP) described in EPA method 1311. Solubilisation tests must be applied to non-hazardous waste to establish it as inert or noninert, i.e., whether or not the parameters, after solubilization, are below maximum limits of potable water. The method is established by Norm NBR 10006 [8].

According to these tests, the waste material can be classified as hazardous (Class I), and Class IINon-hazardous, being that the last one is divided into Class II A- not inert and Class II B- inert.

TABLE 6 and 7 shows the results of the acetic acid leaching, and water solubilisation tests, respectively, and the limit values determined by the Brazilian Standard NBR 10004 [14]. All metal concentrations in the extract leachate (TABLE 6) were found to be below the maximum limit established by Annex F of the Norm NBR 10004, so the waste was considered Class II, "nonhazardous waste".

TABLE 7 showed that concentrations of eight trace metals were above the maximum limit allowed by Annex G of the Norm NBR 10004 [14]. Therefore, according to the results obtained, the FGD can be classified as Class II A (non- hazardous/non-inert) material.

Table6. Concentration of elements leachate from FGD and the allowed limit values

\begin{tabular}{|c|c|c|}
\hline Element & Leachate $\left(\mathrm{mg} \mathrm{L}^{-1}\right)$ & Allowed limit $\left(\mathrm{mg} \mathrm{L}^{-1}\right)$ \\
\hline Arsenic & $<0.01$ & 1.0 \\
\hline Barium & 0.44 & 70.0 \\
\hline Cadmium & $<0.01$ & 0.5 \\
\hline Chromium & $<0.05$ & 5.0 \\
\hline Lead & $<0.05$ & 1.0 \\
\hline Mercury & $<0.001$ & 0.1 \\
\hline Selenium & 0.16 & 1.0 \\
\hline Silver & $<0.05$ & 5.0 \\
\hline
\end{tabular}

Table7. Concentration of elements solubilised from FGD and the allowed limit values

\begin{tabular}{|c|c|c|}
\hline Element & Leachate $\left(\mathrm{mg} \mathrm{L}^{-1}\right)$ & Allowed limit $\left(\mathrm{mg} \mathrm{L}^{-1}\right)$ \\
\hline Aluminium & 0.41 & 0.2 \\
\hline Arsenic & $<0.01$ & 0.01 \\
\hline Barium & 7.4 & 0.7 \\
\hline Cadmium & $<0.01$ & 0.005 \\
\hline Chromium & 0.20 & 0.05 \\
\hline Chloride & 535.6 & 250.0 \\
\hline Copper & $<0.02$ & 1.5 \\
\hline Fluorine & 12.5 & 0.3 \\
\hline Iron & $<0.01$ & 0.01 \\
\hline Lead & $<0.05$ & 0.1 \\
\hline Manganese & $<0.02$ & 0.001 \\
\hline Mercury & $<0.001$ & \\
\hline
\end{tabular}


Alkaline Hydrothermal Treatment of the Waste Produced in the Semi-Dry Flue Gas Desulfurization System

\begin{tabular}{|c|c|c|}
\hline Nitrate & 29.9 & 10.0 \\
\hline Selenium & 0.05 & 0.01 \\
\hline Sodium & 359 & 200 \\
\hline Silver & $<0.05$ & 0.05 \\
\hline Zinc & $<0.01$ & 5.0 \\
\hline
\end{tabular}

Inorganic hygroscopic salts such as barium, potassium, sodium and calcium chlorides and nitrates of sodium and calcium are used in the desulfurization process because studies have shown an effective increase in the performance of hydrated lime [15]. Others elements such as $\mathrm{Al}$ and $\mathrm{Cr}$ are primarily associated with fly ash.

Previous studies showed that there is considerable variability of constituents in the leaching of FDG residues [2]. Which, suggests that materials from certain facilities may be acceptable for appropriate disposal and beneficial use scenarios while the same material type from a different facility or the same facility produced under different operating conditions may not be acceptable for the same management scenario.

\subsection{Characterization of Synthesised Products from FGD}

FGD sample was submitted to hydrothermal treatment at different $\mathrm{NaOH}$ concentrations, temperatures, reaction times and solid/liquid ratios (S/L). Experimental parameters and results for the synthesis are presented TABLE 8.

Table8. Experimental conditions of the hydrothermal experiments and products synthesised

\begin{tabular}{|l|l|l|l|l|l|}
\hline Tests & $\begin{array}{l}{[\mathrm{NaOH}]} \\
\left(\mathrm{mol} \mathrm{L}^{-1}\right)\end{array}$ & $\begin{array}{l}\text { Temperature } \\
\left({ }^{\circ} \mathrm{C}\right)\end{array}$ & Time $(\mathrm{h})$ & $\begin{array}{l}\text { S/L Ratio } \\
\left(\mathrm{g} \mathrm{mL}^{-1}\right)\end{array}$ & $\begin{array}{l}\text { Products } \\
\text { Obtained }(*)\end{array}$ \\
\hline 1 & 1.0 & 80 & 24 & 0.1 & $\mathrm{~K} ; \mathrm{HC}$ \\
\hline 2 & 1.0 & 90 & 24 & 0.1 & $\mathrm{~T}-\mathrm{Al} ; \mathrm{K} ; \mathrm{HC}$ \\
\hline 3 & 1.0 & 90 & 48 & 0.1 & $\mathrm{~T}-\mathrm{Al} ; \mathrm{K}$ \\
\hline 4 & 1.0 & 100 & 24 & 0.1 & $\mathrm{~K} ; \mathrm{HC}$ \\
\hline 5 & 3.5 & 90 & 24 & 0.125 & $\mathrm{HS} ; \mathrm{K} ; \mathrm{HC} ; \mathrm{Pr}$ \\
\hline 6 & 4.0 & 90 & 24 & 0.125 & $\mathrm{HS} ; \mathrm{K} ; \mathrm{Pr}$ \\
\hline 7 & 5.0 & 90 & 24 & 0.125 & $\mathrm{HS} ; \mathrm{K} ; \mathrm{Pr}$ \\
\hline 8 & 4.0 & 100 & 24 & 0.06 & $\mathrm{~K} ; \mathrm{HC}$ \\
\hline 9 & 4.0 & 100 & 48 & 0.06 & $\mathrm{~K} ; \mathrm{HC}$ \\
\hline 10 & 4.0 & 100 & 24 & 0.125 & $\mathrm{HS} ; \mathrm{K} ; \mathrm{HC}$ \\
\hline 11 & 4.0 & 100 & 24 & 0.2 & $\mathrm{HS} ; \mathrm{K} ; \mathrm{HC}$ \\
\hline 12 & 4.0 & 100 & 24 & 0.25 & $\mathrm{HS} ; \mathrm{K} ; \mathrm{HC}$ \\
\hline 13 & 3.5 & 100 & 24 & 0.125 & $\mathrm{HS} ; \mathrm{K} ; \mathrm{HC}$ \\
\hline 14 & 3.5 & 100 & 48 & 0.125 & $\mathrm{HS} ; \mathrm{K} ; \mathrm{HC}$ \\
\hline
\end{tabular}

(*)K= Katoite; HC=Hydrocalumite; HS=zeolite hydroxysodalite; $T$-Al=Al-substituted tobermorite; $\quad P r=$ precipitate

FIGURES 5-8 shows the XRD of all products of the hydrothermal treatments. One can observe that hydroxysodalite was the main zeolitic product obtained after activation of FGD in $\mathrm{NaOH}$ solutions, with different grades of crystallinity, depending on the experimental conditions. Along with the zeolitic product (HS), katoite (K), hydrocalumite (HC) and Al-substituted tobermorite (T-Al) were observed too.

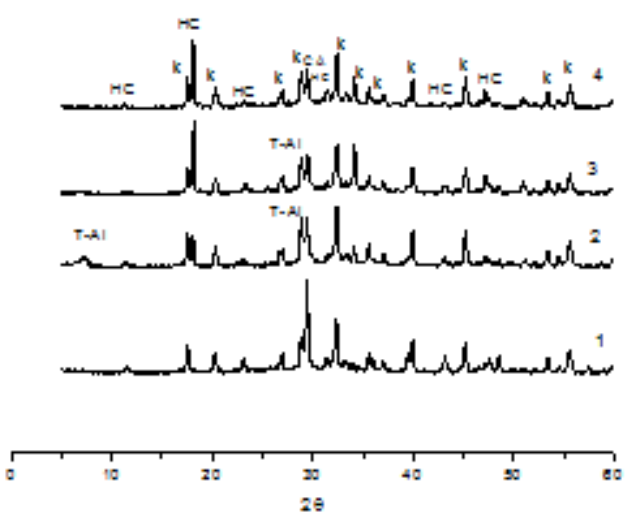

Figure5. XRD patterns of the products of the hydrothermal treatments at different temperatures: tests 1-4 


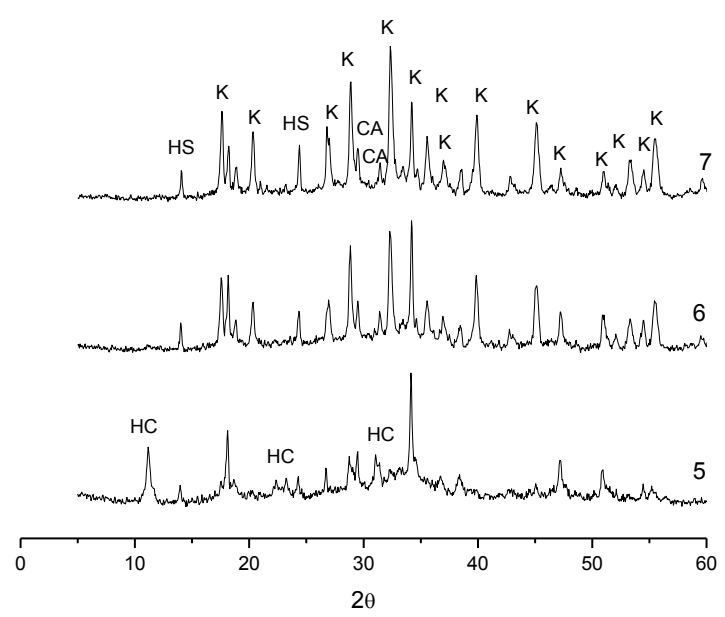

Figure6. XRD patterns of the products of the hydrothermal treatments at different NaOH concentration: tests 5-7

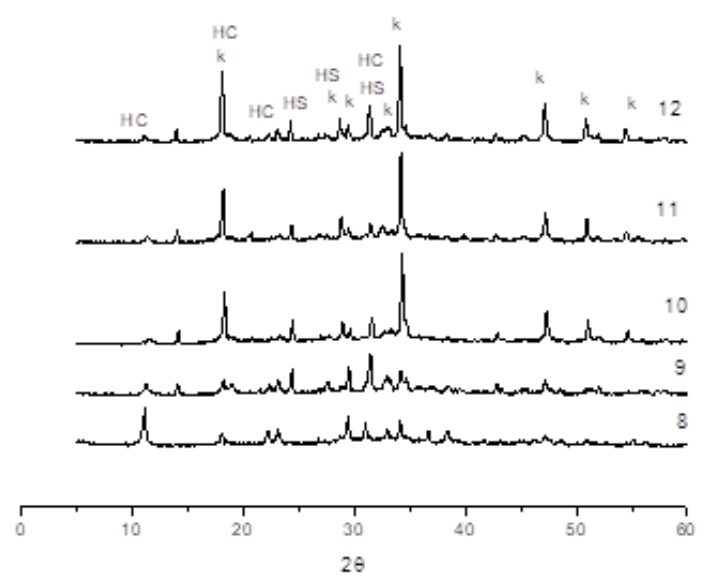

Figure7. XRD patterns of the products of the hydrothermal treatments at different FGD/NaOH ratios: tests 8 12

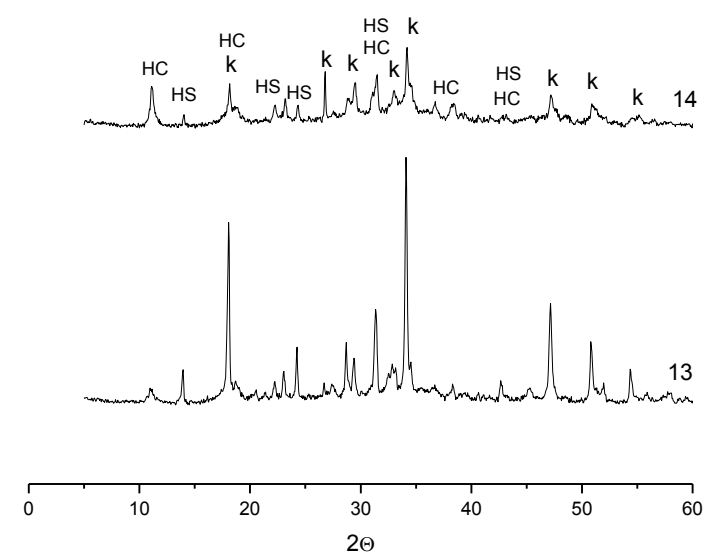

Figure8. XRD patterns of the products of the hydrothermal treatments at different reaction time: tests 13-14

In the set of experiments with $\mathrm{NaOH} 1 \mathrm{~mol} \mathrm{~L}^{-1}$ and different temperatures (Table 8, tests 1-4, Fig. 5) zeolitic material was not detected with $24 \mathrm{~h}$ and $48 \mathrm{~h}$ of reaction. The products obtained were katoite and hydrocalumite. Al-substituted tobermorite was observed only at $90^{\circ} \mathrm{C}$. 
In the set of experiments with different concentrations of $\mathrm{NaOH}$ at $90{ }^{\circ} \mathrm{C}$ (Table 9, tests 5-7, Fig. 6), XRD showed hydroxysodalite as zeolitic phase and katoite. Hydrocalumite appeared at lower $\mathrm{NaOH}$ concentration. There was a white precipitate in the filtrate, which after drying, was identified by XRD as calcite and wollastonite.

In the set of experiments at $100{ }^{\circ} \mathrm{C}$ and $\mathrm{NaOH} 4$ mol L-1 (Table 8, tests 8-12, Fig. 7), the products obtained were hydroxysodalite, katoite and hydrocalumite. Hydroxysodalite was not observed at lower solid/liquid ratio for $24 \mathrm{~h}$ and $48 \mathrm{~h}$ of reaction.

In the set of experiments at $100{ }^{\circ} \mathrm{C}$ and $\mathrm{NaOH} 3.5 \mathrm{~mol} \mathrm{~L}^{-1}$ (Table 8, tests 12-14, Fig. 8), the products obtained were the same of tests 5-7. However, the precipitate was not observed, probably due to the higher temperature used in this experiment.

The kinetics and reaction mechanism and the synthesised products from the hydrothermal processing of $\mathrm{CaO}-\mathrm{SiO}_{2}-\mathrm{Al}_{2} \mathrm{O}_{3}$ materials, like $\mathrm{FGD}$, are strongly affected by the ratio of each component, reaction time, temperature, pressure and the presence of mixtures [16]. In the case of Al-substituted tobermorite, optimum yields are generally achieved from reaction compositions with the following molar component ratios:

$0.80 \leq \mathrm{Ca} /\left[\mathrm{SiO}_{2}+\mathrm{Al}_{2} \mathrm{O}_{3}\right] \leq 0.85$

$0 \leq \mathrm{Al} /[\mathrm{Al}+\mathrm{Si}] \leq 0.17$

Previous works have suggested that long reaction times and increasing proportions of aluminium and calcium promote the formation of hydrogarnets, such as katoite, and other calcium silicate hydrates as additional phases to Al-substituted tobermorite [17]-[19].

In general, the formation of hydrocalumite was favoured at lower temperature ranges between 80 and $90{ }^{\circ} \mathrm{C}$, while the formation of Al-substituted tobermorite and katoite increases as the temperature increases [20].

Hydroxysodalite was produced as a main zeolitic phase following the alkaline activation process for FGD sample. FGD is a material with high calcium content, and this element can adversely affect zeolite formation due to competition with sodium for the active sites in the zeolite framework structure and the formation of calcium silicate [21]. However, it has been confirmed that high $\mathrm{CaO}$ content (>16\%) might enable the formation of hydroxysodalite [22].

The formation of hydroxysodalite zeolite, Al-substituted tobermorite and katoite have been shown to be consistent and in agreement with previous studies about alkaline hydrothermal treatment using waste materials with the similar chemical composition to that of FGD [20], [23].

\section{Conclusions}

The chemical composition analysis showed $\mathrm{Ca}$ and $\mathrm{S}$ as the main components of the dry-FGD material, which was expected regarding the desulfurization process and excess sorbent used. Additionally, Al, Si and Fe complete the list of dominant elements in the sample because fly ash is incorporated into the FGD material. The major minerals present in FGD material were hannebachite, portlandite, calcite, calcium sulfate, gehlenite, and sodium carbonate, indicating a high presence of calcium components in the crystalline phases. The dry-FGD can be classified as Class II A (nondangerous/non-inert) materials.

A simple synthetic route to the formation of Al-substituted tobermorite, katoite, hydrocalumite and zeolite hydroxysodalite by hydrothermal treatments of dry-FGD waste has been demonstrated. The type of the products synthesised varied with varying synthesised conditions such as $\mathrm{NaOH}$ concentration, reaction temperature and crystallisation time and solid/solution ratio.

All resulting products can be considered value-added materials due to their potential to immobilise ionic species by an ionic exchange mechanism with application in environmental problems, particularly in wastewater treatment.

The present study also evidence that is possible the obtaining of a chosen product from the hydrothermal method by changing the synthesis parameters to optimise the process. 


\section{ACKNOWLEDGEMENTS}

The authors are grateful to MPX ENERGIA S.A. for financial support and for supplying the semi-dry FGD sample.

\section{REFERENCES}

[1] R. K. Srivastava and W. Jozewicz, 'Flue Gas Desulfurization: The State of the Art', J. Air Waste Manage. Assoc., vol. 51, no. 12, pp. 1676-1688 (2001).

[2] EPRI, 'A Review of Literature Related to the Use of Spray Dryer Absorber Material: Production, Characterization, Utilization Applications, Barriers, and Recommendations. EPRI, Palo Alto, CA and UND EERC CARRC, Grand Forks, ND: 2007. 1014915.', (2007)

[3] G. Sheng, P. Huang, Y. Mou, and C. Zhou, 'Characteristics of fly ash from the dry flue gas desulfurization system for iron ore sintering plants', Environ. Technol., vol. 33, no. 7, pp. 837-844,( 2012).

[4] T. Zaremba, W. Mokrosz, J. Hehlmann, A. Szwalikowska, and G. Stapiński, 'Properties of the wastes produced in the semi-dry FGD installation', J. Therm. Anal. Calorim., vol. 93, no. 2, pp. 439-443, (2008).

[5] J. M. Bigham, D. A. Kost, R. C. Stehouwer, J. H. Beeghly, R. Fowler, S. J. Traina, W. E. Wolfe, and W. A. Dick, 'Mineralogical and engineering characteristics of dry flue gas desulfurization products', Fuel, vol. 84, no. 14-15, pp. 1839-1848, (2005)

[6] M. Wu, Y. Jian, Q. Su, T. Robl, R. Jewell, T. S. Butalia, W. Zhang, and W. Wolfe, 'Dry FGD By-Product Characteristics and Utilization - International Perspective', World of Coal Ash Conference WOCA. Lexington, Kentucky, (2013).

[7] Brazilian Association of Technical Standards, NBR 10005: Leaching Tests. Rio de Janeiro, Brazil,( 2004), p. 10.

[8] Brazilian Association of Technical Standards, NBR 10006: Solubilization Tests. Rio de Janeiro, Brazil, (2004), p. 2.

[9] National Energy Technology Laboratory, 'Commercial Use of Coal Utilization By-products and Technology Trends', Washington, DC, (2003).

[10] D. A. Fungaro, J. Izidoro, F. Santos, and S. Wang, 'Coal Fly Ash from Brazilian Power Plants: Chemical and Physical Properties and Leaching Characteristics', in Fly Ash: Sources, Applications and Potential Environmental Impacts, P. K. Sarker, Ed. United States: Nova Science Publishers, (2013), pp. 145-164.

[11] M. Mortson and R. W. Telesz, 'Flue Gas Desulfurization Using Recycled Sodium Bicarbonate', U.S. EPA/DOE/EPRI Comb. Power Plant Air Pollut. Control Symp. "The Mega Symp., pp. 1-6, (2001).

[12] K. Pimraksa, S. Hanjitsuwan, and P. Chindaprasirt, 'Synthesis of belite cement from lignite fly ash', Ceram. Int., vol. 35, no. 6, pp. 2415-2425,( 2009).

[13] J.-L. Fernandez-Turiel, A. Georgakopoulos, D. Gimeno, G. Papastergios, and N. Kolovos, 'Ash Deposition in a Pulverized Coal-Fired Power Plant after High-Calcium Lignite Combustion', Energy \& Fuels, vol. 18, no. 5, pp. 1512-1518,( 2004).

[14] Brazilian Association of Technical Standards, NBR 10004: Solid Waste e Classification. Rio de Janeiro, Brazil, (2004), p. 16.

[15] D. O. Ogenga, Z. O. Siagi, M. S. Onyango, and M. Mbarawa, 'An Overview the Use of $\mathrm{Ca}(\mathrm{OH}) 2 /$ Fly Ash in Flue Gas Desulphurization', R\&D J. South African Inst. Mech. Eng., vol. 24, no. 3, pp. 4-8, (2008).

[16] N. J. Coleman and D. S. Brassington, 'Synthesis of Al-substituted $11 \AA$ A tobermorite from newsprint recycling residue: a feasibility study', Mater. Res. Bull., vol. 38, no. 3, pp. 485-497, (2003).

[17] G. L. KALOUSEK, 'Crystal Chemistry of Hydrous Calcium Silicates: I, Substitution of Aluminum in Lattice of Tobermorite', J. Am. Ceram. Soc., vol. 40, no. 3, pp. 74-80, ( 1957).

[18] S. Diamond, J. L. White, and W. L. Dolch, 'Effects of isomorphous substitution in hydrothermallysynthesized tobermorite', Am. Mineral., vol. 51, p. 388, (1966).

[19] T. MITSUDA, 'SYNTHESIS OF TOBERMORITE FROM ZEOLITE', Mineral. J., vol. 6, no. 3, pp. 143158, (1970).

[20] A. P. Bayuseno, W. W. Schmahl, and T. Müllejans, 'Hydrothermal processing of MSWI Fly Ash-towards new stable minerals and fixation of heavy metals', J. Hazard. Mater., vol. 167, no. 1-3, pp. 250-259,( 2009).

[21] P. Catalfamo, S. Di Pasquale, F. Corigliano, and L. Mavilia, 'Influence of the calcium content on the coal fly ash features in some innovative applications.', in Studies in Environmental Science, vol. 71, no. C, 1997, pp. 599-602. 

System

[22] D. Wu, Y. Sui, S. He, X. Wang, C. Li, and H. Kong, 'Removal of trivalent chromium from aqueous solution by zeolite synthesized from coal fly ash', J. Hazard. Mater., vol. 155, no. 3, pp. 415-423, Jul. 2008.

[23] T. Wajima and K. Munakata, 'Material conversion from paper sludge ash in NaOH solution to synthesize adsorbent for removal of $\mathrm{Pb} 2+, \mathrm{NH} 4+$ and $\mathrm{PO} 43-$ from aqueous solution', J. Environ. Sci., vol. 23, no. 5, pp. 718-724, May 2011.

Citation: L. Grosche et al., "Alkaline Hydrothermal Treatment of the Waste Produced in the Semi-Dry Flue Gas Desulfurization System", International Journal of Advanced Research in Chemical Science (IJARCS), vol. 5, no. 1, pp. 9-19, 2018. http://dx.doi.org/10.20431/2349-0403.0501003

Copyright: (c) 2018 Authors. This is an open-access article distributed under the terms of the Creative Commons Attribution License, which permits unrestricted use, distribution, and reproduction in any medium, provided the original author and source are credited. 